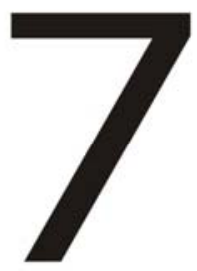

Número
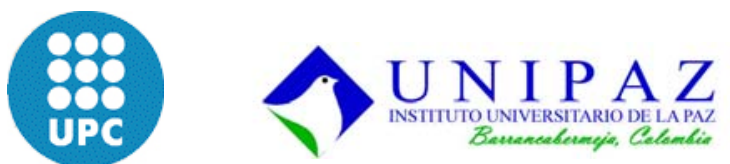

Incluye sección especial de los 10 años de la Ley de Desarrollo Territorial 388 de 1997 de Colombia 
Año III | Número 7 | junio 2008

ISSN on-line: 1886-4805

ISSN papel: 1234-5678

Depósito Legal: B.43924-2006

Marca registrada

Director: Josep Roca Cladera

Coordinación especial: Luís Molina López y Carolina Albarracín Granados

Responsable de Redacción: Carlos Marmolejo Duarte

Coordinadora de Redacción: Magda Ulied Seguí

\section{Consejo Científico:}

Horacio Capel Sáez (Univ. de Barcelona)

Lluís Villanueva Bartrina (UPC)

Manel Guardia Bassols (UPC)

Pilar Garcia Almirall (UPC)

Rafael Serra Florensa (UPC)

Daniel González Romero (Univ. de Guadalajara, México)

Hector Gaete Feres (Univ. del Bio-Bio, Chile)

Jean-Paul Laborie (Univ. Toulouse Le Mirail)

José Antonio Pereira Tenedorio (Univ. Nova da Lisboa)

Luigi Fusco Girard (Univ. Federico I de Nápoles)E

Pedro Abramo Campos (Univ. de Rio de Janeiro)

Riccardo Roscelli (Politécnico de Torino)

\section{Comité Editorial:}

Montserrat Moix Bergadà (web master)

Pau Queraltó Ros (web manager)

Malcolm Burns

Rolando Biere Arenas

Alejandro Marambio Castillo

Bahaa Eddine Al haddad

Helena Coch Roure

Xavier Carceller Roque

\section{Corresponsal:}

Blanca Arellano Ramos (México Noroeste)

Demetrio Muñoz (Paises Bajos)

Esperanza Durán de Gámez (Colombia)

Jesús Fitch Osuna (México-Norte)

Jorge Cerda Troncoso (Chile)

Mario Bragagnini (Perú)

Michael Oxley (Reino Unido)

Susana Ruiz (País Vasco y Navarra)

\section{Apoyo Administrativo:}

Carme Salvat Andrés (Administradora)

Esther Balboa Gómez (Secretaria) 


\section{ACE \\ Arquitectura, Ciudad y Entorno}

Revista del Centro de Política de Suelo y Valoraciones de la Universidad Politécnica de Cataluña (UPC) y de la Red Temática Arquitectura, Ciudad y Medio Ambiente.

\section{Índice}

\section{EDITORIAL}

Editorial.

Luís Molina López

\section{Sección de artículos}

Rupturas, imaginarios y utopías: contribución a la visión crítica de la arquitectura y la ciudad.

Daniel González Romero

¿Cuánto estamos dispuestos a pagar por el silencio?: un análisis contingente para la ciudad de Barcelona.

Carlos Marmolejo Duarte y Agustín Frizzera

\section{Sección especial de los 10 años de la Ley de Desarrollo Territorial 388 de 1997 de Colombia}

La ley 388 de 1997 en Colombia: Algunos puntos de Tensión en el proceso de su implementación.

María Mercedes Maldonado Copello

Los instrumentos de planeamiento urbanístico en la Ley 388 de 1997.

Luis Molina López y Carolina Albarracín Granados

Bogotá, D.C. Primera experiencia de recuperación de plusvalía urbana para la colectividad, en el marco de la Ley de Desarrollo Territorial. $\quad 79$ María Clara Vejarano Alvarado

Impactos en las regulaciones del precio de suelo no urbanizado: Caso de estudio Bogotá.

Oscar Borrero Ochoa y Carlos Morales Schechinger 


\section{ACE \\ Arquitectura, Ciudad y Entorno}

Revista del Centro de Política de Suelo y Valoraciones de la Universidad Politécnica de Cataluña (UPC) y de la Red Temática Arquitectura, Ciudad y Medio Ambiente.

Problemática de los procesos de valoración urbanística en términos de la Ley 388 de 1997.

Jorge Gaitán Torres y Jorge Delgado Amaya

Avances del modelo de urbanismo colombiano: Una mirada retrospectiva al análisis de su estructura planteado por García-Bellido en 1998.

Augusto Cesar Pinto Carrillo

Debilidades del nivel regional en el ordenamiento territorial colombiano. Aproximación desde la normatividad política administrativa y de usos del suelo.

Gustavo Adolfo Carrión Barrero

\section{Sección especial del encuentro realizado en la ciudad de Barrancabermeja Colombia. "Los 10 años de la Ley de Desarrollo Territorial: una lectura desde las regiones en Colombia".}

Enajenación de inmuebles en el marco de la Ley 388 de 1997.

Hernando Acuña Carvajal

Ley 388 de 1997: Una década de fortalecimiento legal del ordenamiento ilegal.

Miguel Antonio Espinosa Rico

Eco-región Eje Cafetero: Una experiencia de desarrollo regional en Colombia.

Oscar Arango Gaviria

Modelos de ocupación y zonificaciones territoriales en el Norte de Santander, Colombia (Región Catatumbo).

Guillermo Quintana Machado

Ordenamiento territorial en el Departamento del Atlántico:

Estado del arte.

Javier Quitian Quintero

Comuna 7 de Barrancabermeja: Una propuesta participativa de ordenación territorial en barrios de origen informal. 


\section{ACE \\ Arquitectura, Ciudad y Entorno}

Revista del Centro de Política de Suelo y Valoraciones de la Universidad Politécnica de Cataluña (UPC) y de la Red Temática Arquitectura, Ciudad y Medio Ambiente.

\section{Sección de tesis y tesinas}

Modelli di urbanizzazione costiera: morfologia e complessità strutturale, a scala urbana e territoriale, nella Regione Metroplitana di Barcellona.

Nicola Colaninno y Josep Roca Cladera

Aportaciones a la diagnosis territorial de Menorca.

Comparación con las directrices del Plan Territorial Insular (2003).

Aina González Puig y David Carreras Martí

\section{Sección de notas}

Breve reseña: Exposición: 5X50 Cinco paisajes por cincuenta años. 313 Magda Ulied Seguí

\section{Abstracts}

Resúmenes de los artículos en inglés. 


\section{Editorial}

La edición número 7 de la revista $A C E$, es producto del trabajo mancomunado entre la Universidad Politécnica de Cataluña y el Instituto Universitario de la Paz (Unipaz), específicamente, a través, del Centro de Política de Suelo y Valoraciones, y del Grupo de Estudios UrbanoRegionales del Magdalena Medio (GEURM). Asimismo, se debe resaltar el inestimable apoyo de la Arq. Esperanza Durán, corresponsal de la Revista ACE en Colombia, y de la Arq. Carolina Albarracín, en la coordinación y logística necesaria para la preparación del monográfico. El presente número, pretende ofrecer un análisis de los avances, retos y perspectivas futuras de la Ley de Desarrollo Territorial (LDT) en Colombia, así como proporcionar elementos para su debate y reflexión, con motivo de los 10 años de su expedición.

Además de la habitual sección de artículos generales, la sección monográfica sobre la LDT incluye 13 contribuciones en dos grandes secciones: una de artículos generales, y otra, dedicada especialmente a las comunicaciones del encuentro realizado en la ciudad de Barrancabermeja Colombia, los días 18 y 19 de julio de 2007, con motivo de la celebración de los 10 años de la Ley 338 de 1997.

En la sección Artículos se presentan 7 aportaciones. En la primera, La Ley 388 de 1997 en Colombia: algunos puntos de tensión en el proceso de su implementación, la profesora María Mercedes Maldonado, Abogada investigadora del Instituto de Estudios Urbanos de la Universidad Nacional de Colombia, examina los contenidos y puntos de discusión, del proceso de implementación de políticas públicas de ordenamiento y suelo en Colombia, así como sus principales tensiones en torno a 3 aspectos centrales: 1) las relaciones entre niveles de gobierno o la distribución de competencias, 2) el régimen jurídico-urbanístico de la propiedad y 3) la articulación entre políticas de suelo y políticas de vivienda de interés social; todo ello, desde el interés creciente que en América Latina se verifica en torno a estos temas, y aportando elementos para la discusión sobre las mejores condiciones de intervención en el mercado del suelo en las ciudades Latinoamericanas. Posteriormente, el profesor y director del GEURM de la Unipaz Luis Molina López y la Arquitecta, asesora del Ministerio de Ambiente Vivienda y Desarrollo Territorial (MAVDT), Carolina Albarracín, en su artículo Instrumentos de planeamiento urbanístico en la Ley 388 de 1997, abordan la estructura general de dicha Ley, así como, explican la jerarquía de los componentes en los planes de ordenamiento, concluyendo con un análisis de la eficacia de los diferentes instrumentos de planeamiento urbano. En el tercer artículo, Bogotá, D.C. Primera experiencia de recuperación de la plusvalía urbana para la colectividad, en el marco de la Ley de Desarrollo Territorial, la Arquitecta y profesora de la Universidad Nacional de Colombia, María Clara Vejarano, expone la primera experiencia de recuperación de plusvalías en la ciudad de Bogotá, al tiempo que desarrolla un pormenorizado análisis de la participación de 


\section{$A C E=$ \\ Arquitectura, Ciudad y Entorno}

las plusvalías en el marco de la Ley 388. Seguidamente, el Economista y avaluador Oscar Borrero Ochoa y el profesor Carlos Morales Schechinger, de la Universidad Nacional Autónoma de México, en su aportación Los impactos de las regulaciones en los precios de suelo no urbanizado: caso de estudio Bogotá, desarrollan un análisis del comportamiento de los precios individuales de suelo en áreas no urbanizadas, demostrando que estos tienden a bajar individualmente, pese a las cargas regulatorias impuestas, de manera contraria a la opinión generada a priori por los demás agentes inmobiliarios. En la quinta aportación, los ingenieros Catastrales y Geodestas, Jorge Gaitán y Jorge Delgado, director de proyectos de ordenamiento territorial y subgerente técnico, respectivamente, de la firma Recaman Koppel, analizan los aspectos técnicos y problemáticos de los procesos de valuación en suelos de expansión, así como en el cálculo del efecto de las plusvalías urbanas, al tenor de lo contemplado en la Ley de Desarrollo Territorial. En la sexta contribución, el Arquitecto Augusto Pinto Carrillo, subdirector de Vivienda y Desarrollo Urbano del Departamento Nacional de Planeación de Colombia, en su artículo Avances del modelo de urbanismo colombiano: Una mirada retrospectiva al análisis de su estructura planteado por Javier García-Bellido en 1998, aborda de forma reflexiva, la implementación de la Ley 388 conjuntamente con las críticas y recomendaciones planteadas por García-Bellido en 1998, acerca de las perspectivas del nuevo urbanismo colombiano. En el último artículo de esta sección, el ingeniero Catastral y Geodesta, asesor del MAVDT, Gustavo Carrión Barrero, realiza en profundidad en su contribución, Debilidades del nivel regional en el ordenamiento territorial colombiano. Aproximación desde la normatividad político administrativa y de usos del suelo, un análisis crítico de la puesta en práctica de la legislación referente a los aspectos regionales del ordenamiento territorial colombiano, con un enfoque desde la organización político administrativa y de usos del suelo propuestos, para las diferentes entidades territoriales.

La segunda sección del monográfico, dedicada a las comunicaciones del encuentro 10 años de la Ley de Desarrollo Territorial: Una lectura desde las regiones de Colombia, está compuesta por 6 contribuciones.

La primera, del profesor Hernando Acuña Carvajal, coordinador de la Especialización en Avalúos de la Universidad Distrital de Bogotá, acerca de la Enajenación de inmuebles en Colombia en el marco de la Ley 388 de 1997, explicita los grandes inconvenientes técnicos, a la hora de realizar las valoraciones de inmuebles, para ello aborda los conceptos de enajenación forzosa y voluntaria, lucro cesante y daño emergente, como aspectos centrales de conflicto en el cálculo técnico de los avalúos inmobiliarios con fines de uso público, en este contexto, el contraste de este articulo con los presentados en la primera sección, proporcionará al lector, una visión más amplia de las distintas posiciones, dificultades técnicas y formas de solución, en la aplicación de ciertos instrumentos contemplados en la Ley de Desarrollo Territorial colombiana. La segunda contribución, Ley 388 de 1997: Una década de fortalecimiento legal del ordenamiento ilegal, del profesor Miguel Espinosa Rico, subdirector del GEURM, desarrolla un balance crítico, de la aplicación de la Ley 388 en los departamentos de Huila y Tolima, y de cómo en algunas ocasiones la 
Ley ha sido objeto de manipulaciones inescrupulosas en el favorecimiento de grandes propietarios de tierras urbanas y rurales, de igual forma, señala algunas experiencias positivas llevadas a cabo en el Departamento del Huila y su articulación interinstitucional, en pro de resultados claramente observados en la implementación de los instrumentos contemplados en la Ley. Seguidamente, el profesor Oscar Arango Gaviria, director del Comité Técnico Alma Mater, en su artículo Ecorregión Eje Cafetero: Una experiencia de desarrollo regional en Colombia, expone la propuesta de desarrollo regional de la Ecorregión Eje Cafetero, haciendo especial énfasis en los procesos urbano-regionales y de metropolización, acorde con el marco general de la Ley 388, así como de los principales componentes de las agendas para el desarrollo propuestas para la Ecorregión. La cuarta aportación, del ingeniero Catastral y Geodesta, Guillermo Quintana Machado, investigador del GEURM, en su contribución sobre Modelos de ocupación y zonificaciones territoriales en Norte de Santander, Colombia (Región Catatumbo), realiza una caracterización general del estado actual del ordenamiento municipal en el Departamento de Norte de Santander, al tiempo que sintetiza las zonificaciones y modelos de ocupación en la región del Catatumbo, con una visión integral, que aborda el papel actual y futuro de lo institucional y los retos en los distintos niveles e instancias territoriales de decisión. Posteriormente, la contribución sobre el ordenamiento territorial en el Departamento del Atlántico: Estado del arte, el ingeniero Catastral y Geodesta, Javier Quitian Quintero, asesor de la Secretaría Distrital del Hábitat de Bogotá, desarrolla una lectura actualizada de la formulación y revisión de planes de ordenamiento territorial en la región Caribe, con una perspectiva ambiental y desde la ordenación de cuencas hidrográficas. Finalmente, en el último artículo, Comuna 7 de Barrancabermeja: Una propuesta participativa de ordenación territorial en barrios de origen informal, el profesor Luis Molina, cierra esta sección de la Revista ACE, presentando una experiencia novedosa de planeamiento participativo, desarrollada por un grupo de líderes comunitarios, que han utilizado los instrumentos contemplados en la Ley 388, para construir una propuesta local de ordenación territorial con perspectiva regional.

La sección de artículos generales está formada por dos aportaciones. La primera está firmada por el Dr. Arquitecto Daniel González Romero del Centro Universitario de Arte, Arquitectura y Diseño. En concreto el autor realiza una reflexión sobre la teoría de la arquitectura en un momento en el cual la arquitectura y el urbanismo están envueltos en procesos de mercado global y consumo, está colmada de símbolos monopólicos formales y estructurales, que producen unas dinámicas en cuyos extremos se producen asimetrías que derivan en la dualidad pobrezariqueza, inclusión-exclusión y estética-ética. Dicho análisis deriva en la comprensión de que la arquitectura, en tanto hecho histórico, forma parte de la autogeneración de la sociedad, y expresa, en tanto manifestación física, la complejidad de las contradicciones sociales. Es por tanto la síntesis estético-técnica, social-histórica que no solo es consecuencia sino también causa de interpretaciones ideológicas. El segundo artículo elaborado por el Dr. Carlos Marmolejo y el Sociológico Agustín Frizzera, tiene un enfoque más específico y pragmático. A través del uso de la 


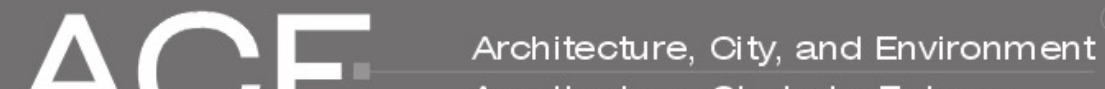 \\ Arquitectura, Ciudad y Entorno}

Revista del Centro de Política de Suelo y Valoraciones de la Universidad Politécnica de Cataluña (UPC) y de la Red Temática Arquitectura, Ciudad y Medio Ambiente.

valoración ambiental, y más específicamente de la valoración contingente, los autores pretenden encontrar el valor que, para el conjunto de la sociedad barcelonesa, tiene el silencio ambiental. Sus resultados dejan ver que el ruido ambiental, en una ciudad compacta, diversa y que utiliza intensivamente el espacio público como Barcelona, produce un impacto tal sobre el bienestar de las personas, que incluso éstas estarían dispuestas a pagar por reducirlo. Así, la disposición a pagar (DAP) media se equipara a un $0,28 \%$ de la renta familiar disponible, una cifra bastante parecida a la encontrada por otros estudios en el Estado Español, pero inferior a lo reportado en otras ciudades europeas.

Finalmente la sección de artículos de tesis resume el trabajo del Arquitecto Nicola Colaninno, dirigido por el Dr. Josep Roca, sobre el análisis de la forma urbana mediante el uso de información derivada de la interpretación de imágenes del satélite Landsat. A través de un conjunto de indicadores cuantitativos llegan a medir la influencia que, sobre los patrones de urbanización, a escala territorial y urbana, tiene el sistema costanero en la Región Metropolitana de Barcelona. Sus principales conclusiones señalan que a medida que nos alejamos de la costa la densidad, continuidad y complejidad formal disminuyen de manera sistemática a lo largo del sistema metropolitano. Y las aportaciones a la diagnosis territorial de Menoría. Comparación con las directrices del Plan Territorial Insular (2003) de Aina González y David Carreras.

Y en la sección de notas encontramos una breve reseña de la Exposición: $5 \times 50$ Cinco paisajes por cincuenta años organizado por el Ministerio de Vivienda.

Luís Molina López 